\title{
Patient-specific induced pluripotent stem cells in neurological disease modeling: the importance of nonhuman primate models
}

This article was published in the following Dove Press journal:

Stem Cells and Cloning:Advances and Applications

2 July 2013

Number of times this article has been viewed

\author{
Zhifang Qiu',2 \\ Steven L Farnsworth ${ }^{2}$ \\ Anuja Mishra ${ }^{1,2}$ \\ Peter J Hornsby ${ }^{1,2}$
}

'Geriatric Research Education and Clinical Center, South Texas Veterans Health Care System, San Antonio, TX, USA; ${ }^{2}$ Barshop Institute for Longevity and Aging Studies, University of Texas Health Science Center, San Antonio, TX, USA
Correspondence: Peter J Hornsby Barshop Institute for Longevity and Aging Studies, University of Texas Health Science Center, 15355 Lambda Drive, San Antonio, TX 78245, USA

$\mathrm{Tel}+\mathrm{I} 2105625080$

$\mathrm{Fax}+\mathrm{I} 2815823538$

Email hornsby@uthscsa.edu

\begin{abstract}
The development of the technology for derivation of induced pluripotent stem (iPS) cells from human patients and animal models has opened up new pathways to the better understanding of many human diseases, and has created new opportunities for therapeutic approaches. Here, we consider one important neurological disease, Parkinson's, the development of relevant neural cell lines for studying this disease, and the animal models that are available for testing the survival and function of the cells, following transplantation into the central nervous system. Rapid progress has been made recently in the application of protocols for neuroectoderm differentiation and neural patterning of pluripotent stem cells. These developments have resulted in the ability to produce large numbers of dopaminergic neurons with midbrain characteristics for further study. These cells have been shown to be functional in both rodent and nonhuman primate (NHP) models of Parkinson's disease. Patient-specific iPS cells and derived dopaminergic neurons have been developed, in particular from patients with genetic causes of Parkinson's disease. For complete modeling of the disease, it is proposed that the introduction of genetic changes into NHP iPS cells, followed by studying the phenotype of the genetic change in cells transplanted into the NHP as host animal, will yield new insights into disease processes not possible with rodent models alone.
\end{abstract}

Keywords: Parkinson's disease, pluripotent cell differentiation, neural cell lines, dopaminergic neurons, cell transplantation, animal models

\section{Introduction}

Since the Nobel prizewinning discovery that somatic cells can be reprogrammed to a pluripotent state, ${ }^{1,2}$ there has been much anticipation that this technology will prove to be of extraordinary value in modeling complex human diseases. For many diseases, it is well known that the combination of a genetic predisposition and various environmental factors synergize to cause the disease. However, the pathophysiology of the disease is often extraordinarily difficult to study, because the cells that are of most relevance are not easily accessible and may be very difficult to maintain in a functional state in vitro. The development of induced pluripotent stem (iPS) cells has opened up a path to solving these problems. ${ }^{3,4}$ Once the main technological barrier had been breached, ie, the conversion of the differentiated somatic cell to a pluripotent cell, it became evident that this could be used with patients' cells to investigate their disease by derivation of appropriate differentiated cells. ${ }^{5,6}$ In this review, we take one important neurodegenerative disease, Parkinson's, as the example. For the investigation of this disease and for studies of new therapeutic strategies, the questions are: (1) are there differences in patient-derived cells of a relevant type, dopaminergic neurons, 
compared to control cells?; (2) can these cells be used to search for new therapies?; and (3) can these cells be used in suitable animal models to recapitulate the disease and the potential therapies for the disease? While many neurological diseases are candidates for cell therapy, Parkinson's disease is a particularly attractive target, because prior studies have shown effectiveness of transplanted tissue in human-patient studies. ${ }^{7-10}$

An important topic is the equivalence of iPS cells and embryonic stem (ES) cells. Early reports suggested that properties of iPS cells might include more restricted differentiation potential than that of ES cells, and a higher tendency for iPS cells to differentiate to the somatic cell of origin of the cells, versus other lineages. ${ }^{11}$ However, increasing evidence suggests that while iPS cell lines may indeed be variable, careful selection of the cell line for extensive study can allow the use of pluripotent cells that are entirely the equivalent of ES cells. ${ }^{12,13}$

\section{The importance of nonhuman primate models}

Evidently, rodent models are of great importance in any disease study, but they may have considerable limitations (Table 1). Nonhuman primates (NHPs) form very valuable models in many situations where rodents are of limited usefulness. Of course, the use of NHPs is certainly not without its problems. They are considerably more expensive to raise and house than rodents, and the relevant basic biology of each species needs to be established; typically, various aspects of NHP biology are less well established than in rodents. On the other hand, when fully implemented, an NHP model may yield sophisticated insights into

Table I Some major differences between primates and rodents that are relevant to the topic of this review

Significant differences between primates and rodents

I. Pluripotent cells (embryonic stem cells and iPS cells) are at a different developmental stage in primates and rodents.

2. Conditions for pluripotent growth in culture are different.

3. Strategies for neural differentiation from pluripotent cells are different.

4. The central nervous system of primates is substantially more complex than that of rodents, and some circuitry is different.

5. Behavioral tests and tests of learning and memory are limited in rodents in comparison to tests that can be performed in primates.

6. Some drugs and toxins act in primates and not in rodents, and vice versa.

7. Differences in the immune-system reaction to pathogens.

Notes: Because of the significant differences between primates and rodents, nonhuman primate models have an important role in the development of patientspecific induced pluripotent stem (iPS) cells for neurological disease modeling. disease processes that cannot be achieved by using rodents. For example, a genetic susceptibility for a disease may simply not be reproducible in a rodent, or even in human cells introduced into a rodent host. If the patient-specific genetic change could be made in NHP cells, and then those cells are introduced into a syngeneic or autologous NHP host, the model could potentially reveal details of the disease process that go well beyond whatever can be determined in rodents. Figure 1 shows a general scheme for the use of iPS cells in neural disease modeling.

NHPs are thought to be ideal for translational research because of their relatedness to humans and their similar physiology, particularly with respect to the central nervous system. Long-term studies of transplanted cell function ( $>3$ years) will be possible in NHPs, but are impossible in rodents. Within nonhuman primates, the major species that have been extensively used are the rhesus macaque (Macaca mulatta), the pigtailed macaque (M. nemestrina), the cynomolgus monkey (M. fascicularis), and the common marmoset (Callithrix jacchus). The marmoset, as a small, short-lived, and rapid-breeding NHP species, has some unique advantages for long-term efficacy and safety studies. In contrast to humans, where uncontrolled environment and many comorbidities are confounding factors, marmosets can be housed in a defined environment and have few known comorbidities. ${ }^{14} \mathrm{~A}$ variety of human diseases can potentially be modeled in marmosets. ${ }^{15-17}$ Specifically, in the present context, a 1-methyl-4-phenyl-1,2,3,6-tetrahydropyridine (MPTP)-induced model of Parkinson's disease has been well characterized in this species. ${ }^{18-20} \mathrm{~A}$ stroke mode ${ }^{21}$ has been developed in this species; histological and magnetic resonance imaging brain atlases are available. ${ }^{22}$ The marmoset genome has been completed,,$^{23,24}$ and the marmoset is the first and so far only primate to have transgenic models that show germ-line transmission. ${ }^{25}$ A genetic model of Parkinson's disease by overexpression of $\alpha$-synuclein has been developed in the marmoset. ${ }^{25}$ Finally, a spinal cord injury model in the marmoset has been used in tests of transplanted human neural stem cells for potential therapeutic effects. ${ }^{26,27}$

\section{Development of transplantable neural cell lines}

For establishing models for both normal neural function and neurological diseases, cells of appropriate lineages must be derived and matured in vitro to a stage suitable for further studies. The last stage of differentiation, to a completely mature cell type, may take place in vivo (following cell transplantation) or in vitro. Transplanting fully mature 


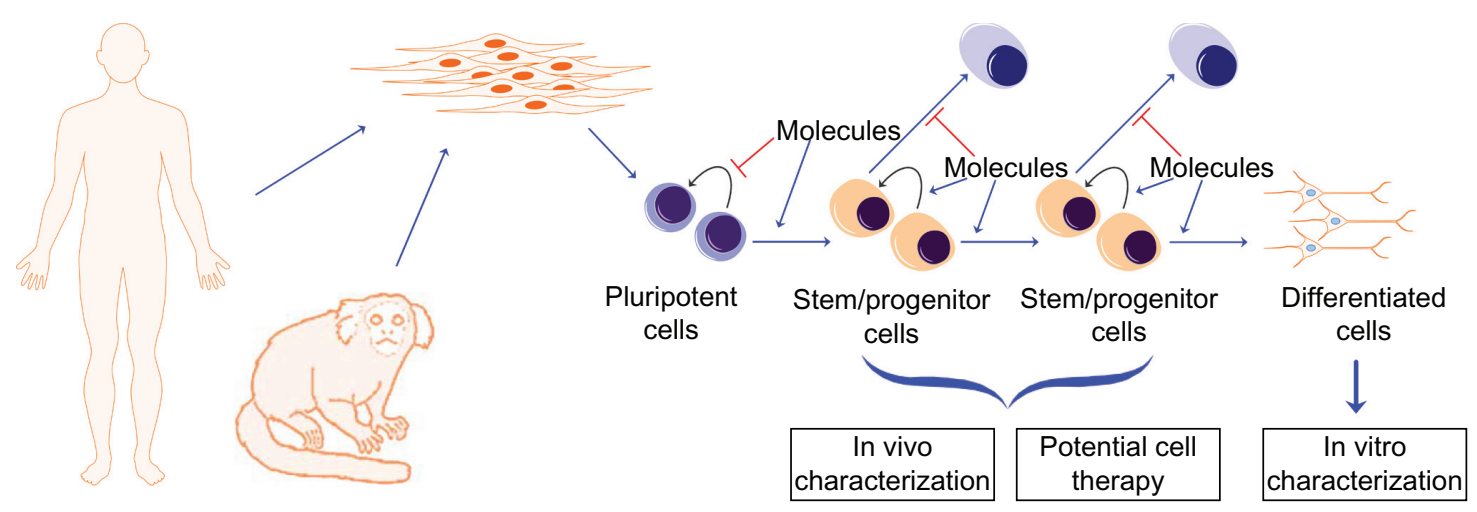

Figure I Scheme for development and use of disease-specific induced pluripotent stem cells.

Notes: A somatic cell type, such as skin fibroblasts, from human patients or from animal models, is reprogrammed to induced pluripotent stem cells. Directed differentiation is used to derive stem/progenitor cells and finally fully differentiated cells in vitro. The diagram illustrates the basic principle underlying protocols that aim for efficient and rational differentiation of pluripotent cells. A typical differentiation protocol goes through multiple stages, attempting to mimic embryonic development by using molecules to stimulate the pathways that are required, while using the same or other molecules to block unwanted differentiation to other pathways at each stage. In this diagram, intermediate cell populations are termed "stem/progenitor cells," although they may not directly correspond to any population of cells found in actual tissues in vivo, either in the embryo or the adult. At the end of the process illustrated here, the aim is to have a population of cells that are suitable for cell therapy or for other purposes. The characterization of the differentiated cells in vitro enables the analysis of the phenotype of cells derived from patients with known genetic diseases or genetic changes, and screening for disease mechanisms and small-molecule therapies in cells from such patients. Human cells can be transplanted into model species for various aspects of disease modeling. When cells are derived from a model animal species, such as the marmoset illustrated here, they can be transplanted back into the same host species, enabling novel aspects of disease modeling.

cells is less likely to give good results, as such cells may be easily damaged, both physically and by the changing environment. A robust form of cell at the transplantable stage should be developed; these cells can be derived in a way that permits their continued proliferation, for extensive and perhaps indefinite periods. In this review, we focus on Parkinson's disease as a target, with dopaminergic neurons as the transplantable cell type and as the cell type for a variety of in vitro studies.

\section{The major problems for transplantable cell-line development}

Figure 2 illustrates the different issues for cell-line development. In this scenario, it is assumed that pluripotent cells will be used and differentiated to a neural cell line. An alternative to the derivation of iPS cells is the direct reprogramming of differentiated somatic cells to a neural lineage..$^{28,29}$ Increasingly, this option is being selected as the technique of choice. The complex topic of direct reprogramming to neural cell lineages is beyond the scope of this review, but has been discussed in detail elsewhere. ${ }^{29}$ Whereas the molecular mechanisms involved in reprogramming to the pluripotent state have partially been elucidated, the molecular circuitry involved in direct reprogramming to neural cells is much less understood. The derivation of neural cells via the iPS cell route has the advantage of versatility, in that once the line is developed, it can be used for the generation of any desired cell type. Additionally, by taking the cells through a recapitulation of embryonic development, we take advantage of known and established pathways of differentiation that have been established by studying early embryos and human embryonic stem cells in culture. ${ }^{30}$ Some of these advantages are lost when a direct reprogramming method is employed. Moreover, it is possible that forced patterning of the wrong progenitor cells may result in artifacts of unstable neuronal cell lines that cannot survive transplantation or do not give rise to functional neurons in vivo; thereby indicating that to produce the most appropriate differentiated cell populations for further study, bona fide developmental pathways should be followed in the directed differentiation of pluripotent cells. ${ }^{31}$

Following the development of satisfactory techniques for the continuous propagation of pluripotent cells, the next step is the commitment of the cells to a desired lineage. In this process, cells are exposed to environmental conditions

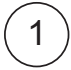

Conditions for pluripotent cell growth - maintenance of pluripotency

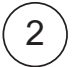

Protocols for differentiation - commitment to a desired lineage
3

Selection of cells of desired lineage
(4)

Conditions for long-term growth of stem/progenitor cells of desired lineage

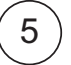

Conditions for differentiation to mature cells

Figure 2 An overview of the different issues that must be solved for the successful development of cell lines from pluripotent cells. 
and mixtures of factors to mimic the early stages of embryogenesis, principally the formation of the neural tube. An important recent conceptual advance is the distinction between late and early patterning. ${ }^{31,32}$ In late patterning, the early stage of the in vitro differentiation process is the formation of neuroectoderm, presumably the equivalent of neural tube formation, followed by patterning based on exposure to morphogens at a later stage. In early patterning, induction of the neuroectodermal lineage and patterning take place in a single combined step (Figure 3).

In recent studies in this lab, we used a form of early patterning in which a combinatorial approach, using various concentrations of small molecules, was studied in an iterative protocol, the measured outcome being increases in expression of various neural lineage genes (Figure 4). We used drugs and factors that had previously been shown to have roles in this early patterning in combinations of 3-D structures and monolayer cultures. We proposed that the use of an iterative combinatorial approach would improve the efficiency of determining optimized early differentiation protocols. Subsequently, the selective growth of cells of the desired lineages can be used to expand the cell population to a stage that can be used for further in vivo or in vitro studies. ${ }^{34}$

\section{Parkinson's disease as a target for cell therapy}

As a consequence of early clinical studies that indicated the promising potential of tissue transplants in Parkinson's disease treatment, ${ }^{7-10}$ the idea of using cells as therapy in this disease has gained momentum. As a neurological disease involving a deficit in a limited region of the brain, Parkinson's disease has been considered a more appropriate target for cell therapy than neurological diseases that involve extensive regions of the brain or that involve multiple tissues throughout the body. The prospects for cell therapy in this disease have been extensively reviewed, and will not be covered in detail here. Tests of cells that could be used in Parkinson's disease therapy require suitable animal models in which efficacy and safety can be thoroughly tested. At some point following animal testing, clinical trials can begin, but most workers in the field would be cautious in beginning human trials based on rodent studies only. Thus, as we discuss here, the choice of animal model is critical not only for demonstrating therapeutic effects but also for adequate disease modeling.

\section{Specific approaches for differentiation of pluripotent cells to dopaminergic neurons}

Methods for the derivation of dopaminergic cells from pluripotent cells have comprised a mixture of practical and rational approaches. Practical approaches are based on observations of the effects of such manipulations as the formation of 3-D structures, coculture with various types of nonneural cells, and exposure to various mixes of defined and undefined factors. Rational approaches, as illustrated in Figure 1, are based on known and suspected regulatory pathways involved in stages of embryogenesis and differentiation. Despite the attractiveness of these logical approaches, their effectiveness for any individual

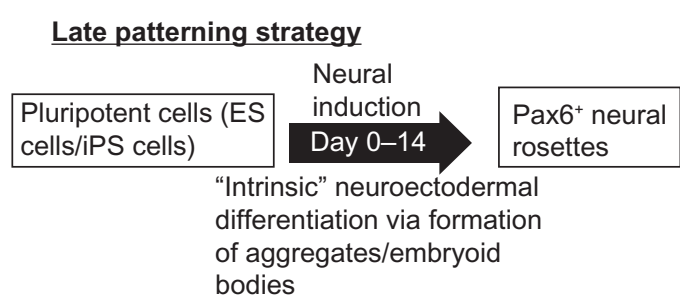

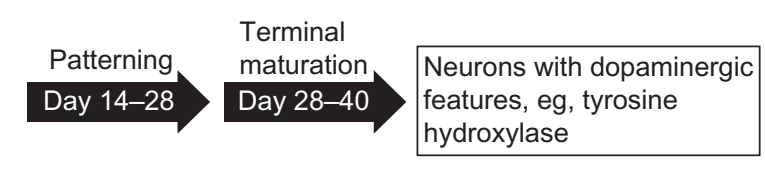
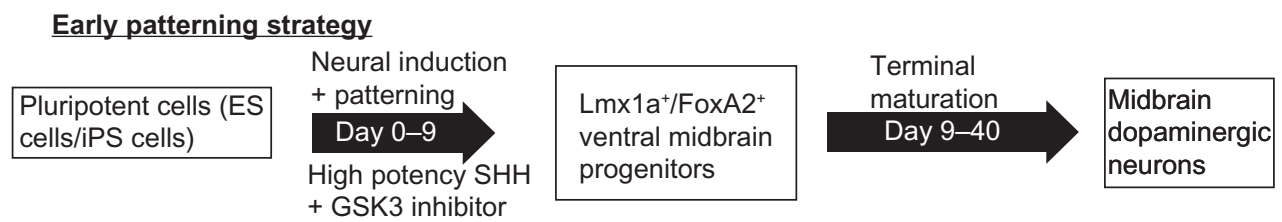

Figure 3 Differentiation of pluripotent cells to neural cells and then to dopaminergic neurons.

Notes: In late patterning, an early induction of neuroectoderm is followed by patterning to specific neural cell types. In early patterning, both the induction and patterning are combined in a single early step. Variations in the induction step in both late and early patterning include the formation of 3-D structures (aggregates or embryoid bodies), as well as treatments of monolayer cells. Formation of 3-D structures may take advantage of the intrinsic tendency of pluripotent cells to differentiate to neural lineages (so-called self formation of layered neural structures ${ }^{33}$ ).

Diagram adapted with permission from Kirkeby A, Parmar M. Building authentic midbrain dopaminergic neurons for stem cells - lessons from development. Transl Neurosci. 2012;3:314-319.31

Abbreviations: ES, embryonic stem; iPS, induced pluripotent stem; $\mathrm{SHH}$, sonic hedgehog. 


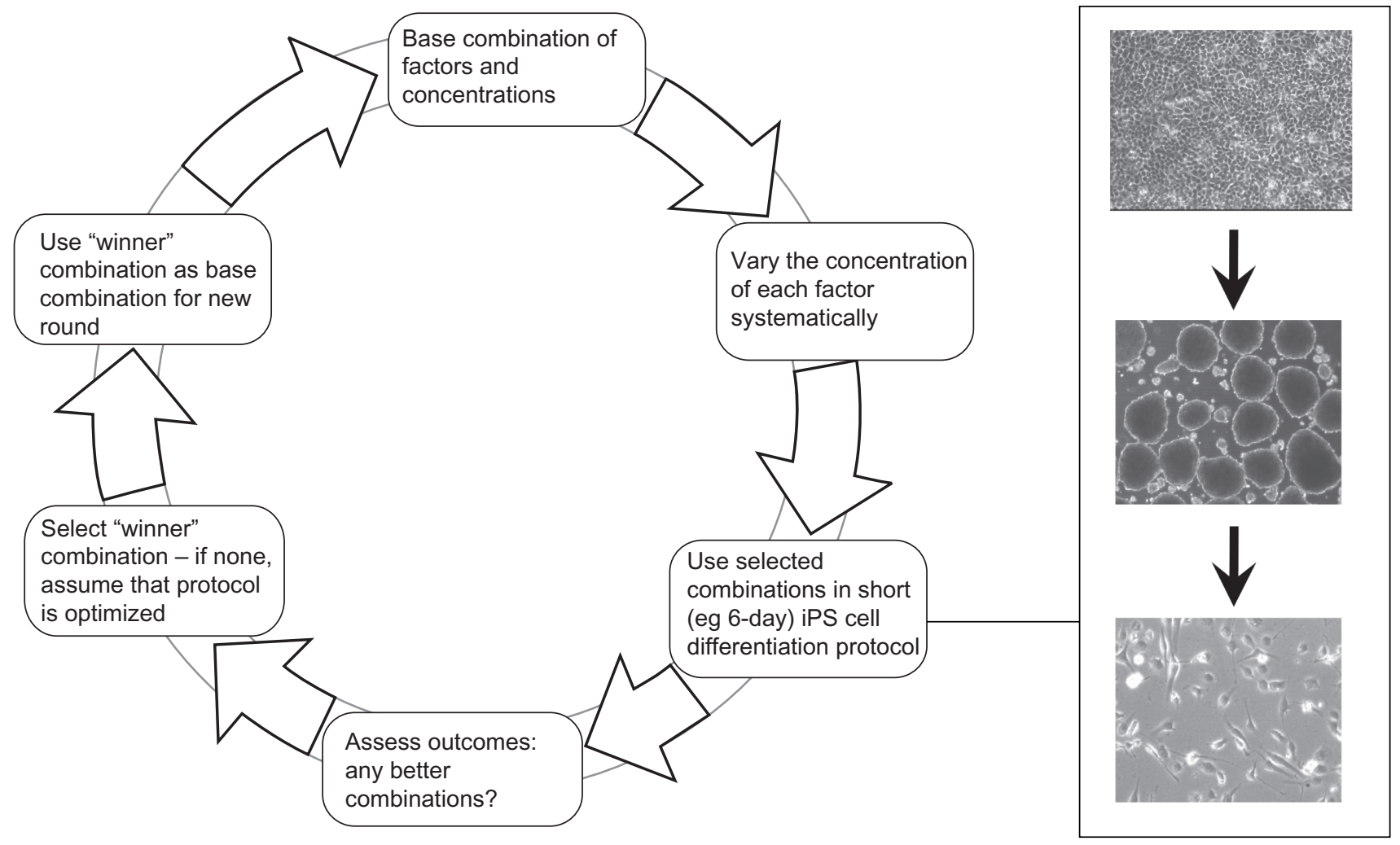

Figure 4 Combinatorial small-molecule approach to early neural patterning for creation of neural cell lines.

Notes: A cyclical process for optimizing differentiation protocols that use combinations of multiple small-molecule drugs or protein factors is shown. In this process, combinations of chemicals/factors are iteratively tested with respect to a desired outcome, ie, the level of differentiation, as assessed by suitable markers. At each round, the outcome is assessed, and a new base combination is selected to begin the new round. The "winner" combination in each round is chosen according to a hill-climbing algorithm. This depends on simultaneous rather than sequential optimization of the drug combinations. The inset panel shows an example of differentiation of marmoset induced pluripotent stem (iPS) cells in a 6-day exposure to drugs/factors. Adapted from Farnsworth et al. ${ }^{34}$

pluripotent cell line is still currently unpredictable. In the present context of differentiation to dopaminergic neurons, it has been observed that different pluripotent cell lines have varying potentials for midbrain differentiation. ${ }^{35}$ Therefore, another general goal for pluripotent cell studies is to determine if all cell lines can be grown under conditions that permit reproducible differentiation to any given desired lineage.

An early practical approach to neural cell-line derivation comprised exposure of pluripotent cells to unidentified factors produced by mesenchymal cells and astrocytes. These factors are collectively termed stromal cell-inducing activity (SDIA), and have been shown to promote neural differentiation generally and dopaminergic neural cell differentiation more specifically. ${ }^{36}$ In the first report of the derivation of human iPS cells, SDIA was used to promote dopaminergic differentiation. ${ }^{2}$ Previously, SDIA-promoted differentiation was shown to produce dopaminergic neurons in cynomolgus ES cells ${ }^{37}$ and rhesus macaque ES cells, ${ }^{38}$ as well as in human ES cells. ${ }^{39}$ Marmoset ES and iPS cells can also be differentiated to neural lineages via the SDIA method. ${ }^{40-42}$

In approaches that mimic the stages of early embryogenesis, cells are taken through the stages of neuroectoderm induction, patterning to specific regions of the brain, and then differentiation to more mature cell types. This has been termed recapitulation of ontogeny. ${ }^{30,43}$ Pluripotent cells readily undergo neuroectoderm differentiation: when they are removed from conditions that maintain pluripotency and are then exposed to a basal supportive medium, they have a strong intrinsic tendency to differentiate to the neural lineage. ${ }^{33,44,45}$ Intrinsic differentiation may be stimulated by formation of a 3-D structure, or may also occur in a monolayer. In a 3-D structure, neuroectodermal differentiation can be recognized by a characteristic neuroepithelial morphology, and in both 3-D structures and monolayers the differentiation is accompanied by the production of adhesion molecules, particularly $\mathrm{N}$-cadherin. ${ }^{45-48}$

Procedures for late patterning with treatment by fibroblast growth factor (FGF)-8 followed by sonic hedgehog ( $\mathrm{SHH}$ ) were described in mouse ES cells, and then applied to human ES cells, ${ }^{49}$ although in this type of protocol the efficiency of producing a population of purely dopaminergic neurons is not high. A representative protocol for neuroectodermal differentiation, followed by patterning to derived dopaminergic cells, is as follows. ${ }^{50}$ 
Detached human ES cells formed floating 3-D structures (variously termed aggregates or embryoid bodies) in a simple medium. After about 6 days of suspension culture, the aggregates were plated on a plastic surface. Within the next few days, the cells elongated and lined up radially in distinct columns; these were primitive neuroectodermal cells. The ridges of columnar cells formed rings with a distinct inner lumen, a structure reminiscent of the neural tube. At this stage, these structures were "neural tube-like rosettes" - definitive neuroectoderm. To caudalize these neuroepithelial cells by addition of morphogens, FGF8 was used for induction of midbrain cells and retinoic acid for induction of midbrain and hindbrain cells. These morphogens resulted in the expression of midbrain and hindbrain markers. In order to generate dopaminergic neurons, the FGF8-induced midbrain progenitors were ventralized by treatment with $\mathrm{SHH}$ to produce dopaminergic cells. However, $<10 \%$ of cells were positive for tyrosine hydroxylase, a marker for dopaminergic neurons. Thus in this representative protocol, pluripotent cells form rostral types of cells by default, which can be caudalized by morphogens and then further differentiated to midbrain dopaminergic neurons. ${ }^{50}$

In a significant advance over such previously employed protocols, rapid neuralization of pluripotent cells by dualSMAD inhibition was shown to permit a prerosette neural stem cell with dopaminergic and motoneuronal potential. ${ }^{51}$ Dopaminergic neuronal patterning was initiated with the addition of an SHH agonist on days 5-9, followed by the addition of a mix of other agents to promote dopaminergic neuron maturation. Modifications of this protocol have been made to substitute other small molecules for those originally used. $^{52-54}$

An important conceptual advance was the distinction between early patterning and late-patterning strategies, ${ }^{31}$ as described earlier (Figure 3). Most of the older differentiation strategies, including many using defined factors, are forms of late patterning, whereas in early patterning, morphogens are applied directly to the pluripotent cells with the aim of directing them to a specific desired neural lineage. In late patterning, there is an initial neuralization (formation of neuroepithelium); once these cultures have been established, the cells are patterned using morphogens relevant for the neurons in question, such as SHH and FGF8 for dopaminergic neurons. However, although the combination of FGF8 and SHH can induce a dopaminergic identity in the differentiating cells, it is not sufficient to restrict the neurons to the midbrain fate..$^{53,55}$ Midbrain dopaminergic neurons are derived from the midbrain floor plate in normal embryogenesis; ${ }^{56}$ logically, therefore, in vitro derivation of dopaminergic neurons that would most closely resemble those lost in Parkinson's disease should attempt to mimic this developmental pathway.

Early patterning is initiated directly in the pluripotent cells, in order to control neural progenitor fates. Patterning toward ventral midbrain is efficiently achieved with a high-potency form of SHH or SHH agonists together with GSK3 inhibition. Midbrain progenitor cells are obtained after 9-10 days; these cells will spontaneously form midbrain dopaminergic neurons, either during maturation in vivo following cell transplantation, or when maintained under maturation conditions in vitro. Glycogen synthase kinase (GSK)-3 inhibition, which activates Wnt signaling, induces forebrain, midbrain, and hindbrain differentiation depending on concentrations of GSK3 inhibitor used. ${ }^{31,53,55}$ In another variation of this approach, GSK3 inhibition was combined with SMAD inhibition and SHH to induce a preneuroepithelial state, required for the floor-plate lineage. Subsequent treatment with $\mathrm{SHH}$, MEK (mitogen-activated protein kinase kinase) inhibitor, and FGF8 produced a high percentage of dopaminergic neurons. ${ }^{57}$ In adapting this approach for rhesus macaque pluripotent cells, an initial period of GSK3 inhibition and high-level SHH was followed by lower SHH and FGF8. ${ }^{55}$

\section{Choice of animal models in Parkinson's disease}

Following differentiation to a suitable stage for transplantation (Figure 1), dopaminergic neuron precursors may be transplanted into the central nervous system in a rodent or NHP model. In rodents, these studies have typically included a functional assay for dopamine production by the cells; these assays are surrogates for treatment of Parkinson's disease, although many aspects of the disease are not readily produced in rodents. ${ }^{58}$ In NHPs, a more valid model of Parkinson's disease can be produced. ${ }^{59}$ In these species, the neurotoxic effects of the agent used to create a Parkinsonian state (MPTP) is very similar to that in humans. The toxic effects on nigrostriatal dopaminergic neurons are similar, and the resultant motor abnormalities resemble those produced by MPTP in humans. The MPTP model in the rhesus macaque has also been used in tests of gene therapy, as well as cell therapy. ${ }^{60}$

In experimental cell therapy, various combinations of species of dopaminergic cell and species of host animal have been used: rodent cells to rodent host; human or NHP cells to rodent host; and human or NHP cells to NHP host. Here, we focus on human and NHP cells in rodent and NHP hosts. As many of these combinations create a xenogeneic 
transplant, differences in results from cross-species and within-species transplants are factors to be considered in interpreting the results. Other considerations are that even a very small population of surviving dopaminergic cells appears to be able to induce functional changes in animal models of Parkinson's disease, and this may involve multiple mechanisms; moreover, the degree of functional improvement does not always seem to correlate with the number of implanted cells. ${ }^{61-63}$

When transplanted in rat Parkinson's models, dopaminergic neurons that have been derived from human ES cells survive and function. The most frequently used rat model comprises transplantation of the cells to the 6-hydroxydopamine-lesioned striatum. Dopaminergic neurons in the substantia nigra $(\mathrm{SN})$ project to the striatum. Therefore, transplantation of cells into the striatum may overcome a deficit of dopamine in this brain region, but transplantation of neurons into the $\mathrm{SN}$, together with subsequent reestablishment of appropriate connections to the striatum, would represent a true reversal of the experimental damage. When successful, animals exhibit recovery of locomotive function and behavioral improvement. Ideally, the improvement correlates with the survival of dopaminergic neurons with midbrain characteristics, which should exhibit mature features and an absence of cell division in vivo.

In pioneering experiments, pluripotent human cells were differentiated by coculture with SDIA-producing cells, and were shown to survive and function in rat models. . $^{39,64-66}$ Similarly, more defined methodology involving differentiation without exposure to SDIA also produced transplantable and functional dopaminergic neurons. ${ }^{67,68}$ Following the development of SHH/FGF8-based patterning, further studies showed that dopaminergic neurons formed by these protocols function in rat models. ${ }^{69-71}$ Protocols based on rapid differentiation and early patterning of human pluripotent cells also produce functional dopaminergic neurons. ${ }^{32,53}$

Dopaminergic neurons derived from human iPS cells also survive and integrate in a Parkinson's disease rat model $;^{72}$ moreover, neurons can be differentiated from iPS cells derived from Parkinson's disease patients, and these cells are functional in a rat model. ${ }^{73}$ In another approach, the transplanted dopaminergic neurons were differentiated from human iPS cells that had been derived by a protein-based reprogramming method. ${ }^{74}$ Additionally, cells derived from NHP iPS cells also survive and function in rat models. ${ }^{75}$

Following experiments on transplantation of dopaminergic neurons into rodent models, cells derived from human and NHP embryonic stem cells were transplanted into NHPs.
In studies to date, these experiments have comprised the transplantation of cells from control subjects (humans and NHPs), and do not yet include transplants of cells derived from human patients with known genetic defects or cells derived from transgenic NHPs. Moreover, only a few studies, mentioned below, involved the transplantation of neurons to the SN, the nucleus that is affected in Parkinson's disease. In 2005 , pioneering studies showed that dopaminergic neurons derived from cynomolgus monkey ES cells survived and functioned at 14 weeks following transplantation in adult male cynomolgus monkeys previously treated with MPTP. The neurological scores of the grafted monkeys improved in comparison with those of sham-operated controls. ${ }^{76}$ Subsequently, in another NHP Parkinson's disease model, in African green monkeys (Chlorocebus sabaeus), dopaminergic neurons derived from human ES cells were shown to improve symptoms when injected into the SN. ${ }^{62}$ The same NHP species has also been used in studies of human neural stem cells not derived from a pluripotent stem cell source. ${ }^{77}$

Subsequently, dopaminergic neurons derived from human iPS cells, differentiated under feeder-free and serum-free conditions, were shown to survive in MPTP-lesioned cynomolgus monkeys for 6 months. ${ }^{78}$ Several studies have also shown the use of MPTP model of Parkinson's disease in the rhesus macaque. Dopaminergic neurons derived from human ES and iPS cells by the floor plate-based differentiation protocol survived for $>1$ month following transplantation. ${ }^{53}$ Dopaminergic neurons from human ES cells have also been transplanted into the $\mathrm{SN} .{ }^{79}$ In a further advance, prolonged maturation of neurons in culture favored a reduction in tumorigenicity in human ES cell-derived neurons. ${ }^{80}$ Most significantly, the first study of dopaminergic neurons derived from autologous cells has been reported in this species. ${ }^{81}$ In this study, iPS cells were first derived from skin fibroblasts, and were later differentiated to dopaminergic neurons by exposure to $\mathrm{SHH} / \mathrm{FGF} 8$. MPTP-lesioned monkeys received magnetic resonance image-guided stereotactic cell injections into the $\mathrm{SN}$ and the striatum. The neural progenitors survived for up to 6 months and differentiated into neurons, astrocytes, and myelinating oligodendrocytes in the brain. The potential importance of derivation via the floor-plate route is suggested by a study in which neurons derived from human ES cells via a modified late-patterning strategy survived transplantation into the SN of African green monkeys, but expected features of dopaminergic neurons were not observed. ${ }^{82}$ In another variation of autologous cell transplantation, forced expression of Notch intracellular domain in cynomolgus monkey mesenchymal stem cells was used to derive dopaminergic 
neurons, which were autologously transplanted in MPTPlesioned animals. ${ }^{83}$ The monkeys showed improvement in a clinical rating score and improvement in a hand-reach test. Although this procedure uses bone marrow mesenchymal stem cells as the starting material, this provides a possible route from pluripotent cells, which can be differentiated to mesenchymal stem cells. However, currently it is not known whether MSC-derived neurons have all the features of pluripotent cell-derived neurons that have undergone a differentiation process that mimics embryogenesis in the central nervous system.

\section{Studying patients' disease via creation of iPS cells and derivation of dopaminergic neurons}

Parkinson's disease is an example of an important neurological condition, which like many such diseases comprises a small number of patients with genetic causes and a much larger number with the disease in which there are presumed genetic influences. In those patients, it is hypothesized that the cause of the disease is the exposure of dopaminergic neurons to environmental or endogenous toxins, and that a genetic susceptibility to these toxins, which may be widespread or universal, creates a higher probability of contracting the disease. Specific genes already determined to be involved in human Parkinson's disease include LRRK2, PARK2, DJ1, PINK1, ATP13A2, $S N C A$, and $G B A .^{84}$

When iPS cells are derived from patients with a known mutation, they can be used to derive neurons for fundamental studies of the phenotype conferred by the mutation, and for translational studies such as screening drugs for efficacy in correcting the disease phenotype. ${ }^{85,86} \mathrm{~A}$ pioneering study involved the derivation of iPS cells, and subsequently of motor neurons, from patients with amyotrophic lateral sclerosis. $^{87}$

The first studies of iPS cells and iPS cell-derived neurons in Parkinson's disease were in patients without known disease-causing mutations. ${ }^{5,6,73}$ Subsequently iPS cells were formed from patients with mutations in $P I N K 1^{88}$ and from patients with a triplication of the $S N C A$ gene, encoding $\alpha$-synuclein. ${ }^{89}$ Significantly, in neurons derived from iPS cells from patients with mutations in $L R R K 2$, various differences from control cells were observed, including an increased susceptibility to oxidative stress. ${ }^{90}$

In a recent tour de force experiment, the gene defect in cells from a patient with a genetic cause of Parkinson's disease was corrected by zinc-finger nuclease (ZFN) technology. ${ }^{91}$
First, iPS cells were derived from a patient with the G2019S mutation in LRRK2. The mutation, in the defective allele, was then corrected in the iPS cells by nucleofection of ZFN constructs targeting $L R R K 2$. Interestingly, ZFNs were also used to introduce the G2019S mutation into one of the $L R R K 2$ loci in a control iPS cell line from a healthy individual. Dopaminergic neurons were then derived from the iPS cells. Several aspects of the phenotype of this mutation, including neurite shortening, sensitivity to neurotoxins and oxidative stress, aberrant autophagy, changes in Tau, and enhanced $\alpha$-synuclein aggregation, were corrected by the ZFN strategy. ${ }^{91}$

As outstanding as these recent studies are, they nevertheless may not be able to elucidate the genetic influences on the disease that are manifest only when the cells are in situ in the central nervous system. Some possible approaches to this issue are to knock in the disease-causing mutation in the mouse, but this might not reveal aspects of the phenotype that are specific to primates. ${ }^{92}$ Therefore, a novel strategy for disease modeling is to reproduce the essential features of the human disease in an NHP model. A possible but complex approach is to generate a transgenic or knock-in model, but in primates this is far from routine. To date, one disease-relevant marmoset model has been generated with overexpression of $\alpha$-synuclein. ${ }^{25}$ Another transgenic model in the rhesus monkey was successful in transgene expression, but failed to achieve germ-line transmission. ${ }^{93}$ However, disease modeling with iPS cells provides a more readily achievable, although still not straightforward, method for studying the phenotype associated with genotypes in Parkinson's or in other diseases. In a primate model, the disease-associated genotype can be introduced into the iPS cells by gene targeting, as illustrated by the introduction of the G2019S mutation into one of the LRRK2 loci in control human iPS cells. ${ }^{91}$ Following the drug-induced neurological deficit in the NHP, the modified cells can be introduced into the animal for comparison with an animal treated with control cells. Of course, the technical difficulties associated with this should not be underestimated. In the case of recessive genes, both copies of the gene or regulatory sequence would need to be replaced. Nevertheless, when this protocol is fully implemented, it will give the most complete picture of the role of the genetic change in the disease phenotype. Of course, an alternative is to use cells derived from human iPS cells in the NHP model, but the cross-species differences, although less than human-rodent differences, may still cause problems of interpretation. These xenogeneic transplants may also require suppression of 
immune rejection, and to what extent such suppression of a xenogeneic immune response might affect the outcome is unknown. It will be very informative to have sufficient evidence to base a decision on whether implanting humanderived cells in the NHP brain is adequate for disease modeling, or if a more exact phenocopy of the disease is obtained with cells of the same species or possibly even the same individual animal.

\section{Acknowledgments}

Work from the authors' laboratory was supported by grant I01BX001454 from the Department of Veterans Affairs to PJH, and also by grants from the Ted Nash Long Life Foundation and the Owens Medical Foundation. SLF was supported by an individual fellowship (F30DE022494) and by the COSTAR training grant T32DE014318.

\section{Disclosure}

The authors report no conflicts of interest in this work.

\section{References}

1. Takahashi K, Yamanaka S. Induction of pluripotent stem cells from mouse embryonic and adult fibroblast cultures by defined factors. Cell. 2006;126:663-676.

2. Takahashi K, Tanabe K, Ohnuki M, et al. Induction of pluripotent stem cells from adult human fibroblasts by defined factors. Cell. 2007;131 861-872.

3. Cohen DE, Melton D. Turning straw into gold: directing cell fate for regenerative medicine. Nat Rev Genet. 2011;12:243-252.

4. Morris SA, Daley GQ. A blueprint for engineering cell fate: current technologies to reprogram cell identity. Cell Res. 2013;23:33-48.

5. Park IH, Arora N, Huo H, et al. Disease-specific induced pluripotent stem cells. Cell. 2008;411:99-110.

6. Soldner F, Hockemeyer D, Beard C, et al. Parkinson's disease patientderived induced pluripotent stem cells free of viral reprogramming factors. Cell. 2009;136:964-977.

7. Sanberg PR. Neural stem cells for Parkinson's disease: to protect and repair. Proc Natl Acad Sci U SA. 2007;104:11869-11870.

8. Brundin P, Barker RA, Parmar M. Neural grafting in Parkinson's disease: problems and possibilities. Prog Brain Res. 2010;184:265-294.

9. Lindvall O, Bjorklund A. Cell therapeutics in Parkinson's disease. Neurotherapeutics. 2011;8:539-548.

10. Lindvall O. Dopaminergic neurons for Parkinson's therapy. Nat Biotechnol. 2012;30:56-58.

11. Barrero MJ, Izpisua Belmonte JC. iPS cells forgive but do not forget. Nat Cell Biol. 2011;13:523-525.

12. Bock C, Kiskinis E, Verstappen G, et al. Reference maps of human ES and iPS cell variation enable high-throughput characterization of pluripotent cell lines. Cell. 2011;144:439-452.

13. Boulting GL, Kiskinis E, Croft GF, et al. A functionally characterized test set of human induced pluripotent stem cells. Nat Biotechnol. 2011;29:279-286.

14. Abbott DH, Barnett DK, Colman RJ, Yamamoto ME, Schultz-Darken NJ. Aspects of common marmoset basic biology and life history important for biomedical research. Comp Med. 2003;53:339-350.

15. Mansfield K. Marmoset models commonly used in biomedical research. Comp Med. 2003;53:383-392.

16. Tardif S, Bales K, Williams L, et al. Preparing new world monkeys for laboratory research. ILAR J. 2006;47:307-315.
17. Cyranoski D. Marmoset model takes centre stage. Nature. 2009; 459:492.

18. Philippens IH, 't Hart BA, Torres G. The MPTP marmoset model of Parkinsonism: a multi-purpose non-human primate model for neurodegenerative diseases. Drug Discov Today. 2010;13: $800-804$.

19. Eslamboli A. Marmoset monkey models of Parkinson's disease: which model, when and why? Brain Res Bull. 2005;68:140-149.

20. Okano H, Hikishima K, Iriki A, Sasaki E. The common marmoset as a novel animal model system for biomedical and neuroscience research applications. Semin Fetal Neonatal Med. 2012;17:336-340.

21. Bihel E, Pro-Sistiaga P, Letourneur A, et al. Permanent or transient chronic ischemic stroke in the non-human primate: behavioral, neuroimaging, histological, and immunohistochemical investigations. $J$ Cereb Blood Flow Metab. 2010;30:273-285.

22. Newman JD, Kenkel WM, Aronoff EC, Bock NA, Zametkin MR, Silva AC. A combined histological and MRI brain atlas of the common marmoset monkey, Callithrix jacchus. Brain Res Rev. 2009; 62:1-18.

23. Kuhn RM, Karolchik D, Zweig AS, et al. The UCSC Genome Browser Database: update 2009. Nucleic Acids Res. 2009;37:D755-D761.

24. Tatsumoto S, Adati N, Tohtoki Y, et al. Development and characterization of cDNA resources for the common marmoset: one of the experimental primate models. DNA Res. 2013;17:336-340.

25. Sasaki E, Suemizu H, Shimada A, et al. Generation of transgenic non-human primates with germline transmission. Nature. 2009;459: $523-527$.

26. Iwanami A, Kaneko S, Nakamura M, et al. Transplantation of human neural stem cells for spinal cord injury in primates. J Neurosci Res. 2005;80:182-190.

27. Yamane J, Nakamura M, Iwanami A, et al. Transplantation of galectin1-expressing human neural stem cells into the injured spinal cord of adult common marmosets. J Neurosci Res. 2010;88:1394-1405.

28. Vierbuchen T, Wernig M. Direct lineage conversions: unnatural but useful? Nat Biotechnol. 2011;29:892-907.

29. Yang N, Ng YH, Pang ZP, SudhofTC, Wernig M. Induced neuronal cells: how to make and define a neuron. Cell Stem Cell. 2011;9:517-525.

30. Muguruma K, Sasai Y. In vitro recapitulation of neural development using embryonic stem cells: from neurogenesis to histogenesis. Dev Growth Differ. 2012;54:349-357.

31. Kirkeby A, Parmar M. Building authentic midbrain dopaminergic neurons for stem cells - lessons from development. Transl Neurosci. 2012;3:314-319.

32. Kirkeby A, Nelander J, Parmar M. Generating regionalized neuronal cells from pluripotency, a step-by-step protocol. Front Cell Neurosci. 2012;6:64

33. Eiraku M, Sasai Y. Self-formation of layered neural structures in three-dimensional culture of ES cells. Curr Opin Neurobiol. 2012;22: 768-777.

34. Farnsworth SL, Qiu Z, Mishra A, Hornsby PJ. Directed neural differentiation of induced pluripotent stem cells from nonhuman primates. Exp Biol Med. 2013;238:276-284.

35. Wu H, Xu J, Pang ZP, et al. Integrative genomic and functional analyses reveal neuronal subtype differentiation bias in human embryonic stem cell lines. Proc Natl Acad Sci U S A. 2007;104:13821-13826.

36. Kawasaki H, Mizuseki K, Nishikawa S, et al. Induction of midbrain dopaminergic neurons from ES cells by stromal cell-derived inducing activity. Neuron. 2000;28:31-40.

37. Mizuseki K, Sakamoto T, Watanabe K, et al. Generation of neural crest-derived peripheral neurons and floor plate cells from mouse and primate embryonic stem cells. Proc Natl Acad Sci U S A. 2003;100: $5828-5833$.

38. Kuo HC, Pau KY, Yeoman RR, Mitalipov SM, Okano H, Wolf DP Differentiation of monkey embryonic stem cells into neural lineages. Biol Reprod. 2003;68:1727-1735.

39. Zeng X, Cai J, Chen J, et al. Dopaminergic differentiation of human embryonic stem cells. Stem Cells. 2004;22:925-940. 
40. Sasaki E, Hanazawa K, Kurita R, et al. Establishment of novel embryonic stem cell lines derived from the common marmoset (Callithrix jacchus). Stem Cells. 2005;23:1304-1313.

41. Tomioka I, Maeda T, Shimada H, et al. Generating induced pluripotent stem cells from common marmoset (Callithrix jacchus) fetal liver cells using defined factors, including Lin28. Genes Cells. 2010;15: 959-969.

42. Wu Y, Mishra A, Qiu Z, Farnsworth S, Tardif SD, Hornsby PJ. Nonhuman primate induced pluripotent stem cells in regenerative medicine. Stem Cells Int. 2012;2012:767195.

43. Muguruma K, Nishiyama A, Ono Y, et al. Ontogeny-recapitulating generation and tissue integration of ES cell-derived Purkinje cells. Nat Neurosci. 2010;13:1171-1180.

44. Liu H, Zhang SC. Specification of neuronal and glial subtypes from human pluripotent stem cells. Cell Mol Life Sci. 2011;68:3995-4008.

45. Kamiya D, Banno S, Sasai N, et al. Intrinsic transition of embryonic stem-cell differentiation into neural progenitors. Nature. 2011;470: 503-509.

46. Curchoe CL, Maurer J, McKeown SJ, et al. Early acquisition of neural crest competence during hESCs neuralization. PLoS One. 2010;5: e13890.

47. Eiraku M, Takata N, Ishibashi $\mathrm{H}$, et al. Self-organizing optic-cup morphogenesis in three-dimensional culture. Nature. 2011;472:51-56.

48. Eiraku M, Sasai Y. Mouse embryonic stem cell culture for generation of three-dimensional retinal and cortical tissues. Nat Protoc. 2012;7:69-79.

49. Yan Y, Yang D, Zarnowska ED, et al. Directed differentiation of dopaminergic neuronal subtypes from human embryonic stem cells. Stem Cells. 2005;23:781-790.

50. Zeng H, Guo M, Martins-Taylor K, et al. Specification of region-specific neurons including forebrain glutamatergic neurons from human induced pluripotent stem cells. PLoS One. 2010;5:e11853.

51. Chambers SM, Fasano CA, Papapetrou EP, Tomishima M, Sadelain M, Studer L. Highly efficient neural conversion of human ES and iPS cells by dual inhibition of SMAD signaling. Nat Biotech. 2009;27:275-280.

52. Kim DS, Lee JS, Leem JW, et al. Robust enhancement of neural differentiation from human ES and iPS cells regardless of their innate difference in differentiation propensity. Stem Cell Rev. 2010;6: 270-281.

53. Kriks S, Shim JW, Piao J, et al. Dopamine neurons derived from human ES cells efficiently engraft in animal models of Parkinson's disease. Nature. 2011;480:547-551.

54. Morizane A, Doi D, Kikuchi T, Nishimura K, Takahashi J. Smallmolecule inhibitors of bone morphogenic protein and activin/nodal signals promote highly efficient neural induction from human pluripotent stem cells. J Neurosci Res. 2011;89:117-126.

55. Xi J, Liu Y, Liu H, Chen H, Emborg ME, Zhang SC. Specification of midbrain dopamine neurons from primate pluripotent stem cells. Stem Cells. 2012;30:1655-1663.

56. Joksimovic M, Yun BA, Kittappa R, et al. Wnt antagonism of Shh facilitates midbrain floor plate neurogenesis. Nat Neurosci. 2009;12: 125-131.

57. Denham M, Bye C, Leung J, Conley BJ, Thompson LH, Dottori M. Glycogen synthase kinase 3 beta and activin/nodal inhibition in human embryonic stem cells induces a pre-neuroepithelial state that is required for specification to a floor plate cell lineage. Stem Cells. 2012;30: 2400-2411.

58. Hantraye P. Modeling dopamine system dysfunction in experimental animals. Nucl Med Biol. 1998;25:721-728.

59. Joers VL, Emborg ME. Preclinical assessment of stem cell therapies for neurological diseases. ILAR J. 2009;51:24-41.

60. Jarraya B, Boulet S, Ralph GS, et al. Dopamine gene therapy for Parkinson's disease in a nonhuman primate without associated dyskinesia. Sci Transl Med. 2009;1:2ra4.

61. Meissner KK, Kirkham DL, Doering LC. Transplants of neurosphere cell suspensions from aged mice are functional in the mouse model of Parkinson's. Brain Res. 2005;1057:105-112.
62. Redmond DE Jr, Bjugstad KB, Teng YD, et al. Behavioral improvement in a primate Parkinson's model is associated with multiple homeostatic effects of human neural stem cells. Proc Natl Acad Sci U SA. 2007;104: 12175-12180.

63. Wei P, Liu J, Zhou HL, et al. Effects of engrafted neural stem cells derived from GFP transgenic mice in Parkinson's diseases rats. Neurosci Lett. 2007;419:49-54.

64. Park CH, Minn YK, Lee JY, et al. In vitro and in vivo analyses of human embryonic stem cell-derived dopamine neurons. J Neurochem. 2005;92:1265-1276.

65. Brederlau A, Correia AS, Anisimov SV, et al. Transplantation of human embryonic stem cell-derived cells to a rat model of Parkinson's disease: effect of in vitro differentiation on graft survival and teratoma formation. Stem Cells. 2006;24:1433-1440.

66. Roy NS, Cleren C, Singh SK, Yang L, Beal MF, Goldman SA. Functional engraftment of human ES cell-derived dopaminergic neurons enriched by coculture with telomerase-immortalized midbrain astrocytes. Nat Med. 2006;12:1259-1268.

67. Iacovitti L, Donaldson AE, Marshall CE, Suon S, Yang M. A protocol for the differentiation of human embryonic stem cells into dopaminergic neurons using only chemically defined human additives: studies in vitro and in vivo. Brain Res. 2007;1127:19-25.

68. Elkabetz Y, Panagiotakos G, Al Shamy G, Socci ND, Tabar V, Studer L. Human ES cell-derived neural rosettes reveal a functionally distinct early neural stem cell stage. Genes Dev. 2008;22:152-165.

69. Yang D, Zhang ZJ, Oldenburg M, Ayala M, Zhang SC. Human embryonic stem cell-derived dopaminergic neurons reverse functional deficit in parkinsonian rats. Stem Cells. 2008;26:55-63.

70. Swistowski A, Peng J, Liu Q, et al. Efficient generation of functional dopaminergic neurons from human induced pluripotent stem cells under defined conditions. Stem Cells. 2010;28:1893-1904.

71. Colleoni S, Galli C, Giannelli SG, et al. Long-term culture and differentiation of CNS precursors derived from anterior human neural rosettes following exposure to ventralizing factors. Exp Cell Res. 2010;316: 1148-1158.

72. Cai J, Yang M, Poremsky E, Kidd S, Schneider JS, Iacovitti L. Dopaminergic neurons derived from human induced pluripotent stem cells survive and integrate into 6-OHDA-lesioned rats. Stem Cells Dev. 2010;19:1017-1023.

73. Hargus G, Cooper O, Deleidi M, et al. Differentiated Parkinson patientderived induced pluripotent stem cells grow in the adult rodent brain and reduce motor asymmetry in Parkinsonian rats. Proc Natl Acad Sci US A. 2010;107:15921-15926.

74. Rhee YH, Ko JY, Chang MY, et al. Protein-based human iPS cells efficiently generate functional dopamine neurons and can treat a rat model of Parkinson disease. J Clin Invest. 2011;121:2326-2335.

75. Deleidi M, Hargus G, Hallett P, Osborn T, Isacson O. Development of histocompatible primate-induced pluripotent stem cells for neural transplantation. Stem Cells. 2011;29:1052-1063.

76. Takagi Y, Takahashi J, Saiki H, et al. Dopaminergic neurons generated from monkey embryonic stem cells function in a Parkinson primate model. J Clin Invest. 2005;115:102-109.

77. Bjugstad KB, Redmond DE Jr, Teng YD, et al. Neural stem cells implanted into MPTP-treated monkeys increase the size of endogenous tyrosine hydroxylase-positive cells found in the striatum: a return to control measures. Cell Transplant. 2005;14:183-192.

78. Kikuchi T, Morizane A, Doi D, et al. Survival of human induced pluripotent stem cell-derived midbrain dopaminergic neurons in the brain of a primate model of Parkinson's disease. J Parkinsons Dis. 2011;1:395-412.

79. Daadi MM, Grueter BA, Malenka RC, Redmond DE Jr, Steinberg GK. Dopaminergic neurons from midbrain-specified human embryonic stem cell-derived neural stem cells engrafted in a monkey model of Parkinson's disease. PLoS One. 2012;7:e41120.

80. Doi D, Morizane A, Kikuchi T, et al. Prolonged maturation culture favors a reduction in the tumorigenicity and the dopaminergic function of human ESC-derived neural cells in a primate model of Parkinson's disease. Stem Cells. 2012;30:935-945. 
81. Emborg ME, Liu Y, Xi J, et al. Induced pluripotent stem cell-derived neural cells survive and mature in the nonhuman primate brain. Cell Rep. 2013;3:646-650.

82. Wakeman DR, Weiss S, Sladek JR, et al. Survival and integration of neurons derived from human embryonic stem cells in MPTP lesioned primates. Cell Transplant. Epub April 2, 2013.

83. Hayashi T, Wakao S, Kitada M, et al. Autologous mesenchymal stem cell-derived dopaminergic neurons function in parkinsonian macaques. J Clin Invest. 2013;123:272-284.

84. Xu L, Xu CJ, Lu HZ, Wang YX, Li Y, Lu PH. Long-term fate of allogeneic neural stem cells following transplantation into injured spinal cord. Stem Cell Rev. 2010;6:121-136.

85. Wichterle H, Przedborski S. What can pluripotent stem cells teach us about neurodegenerative diseases? Nat Neurosci. 2010;13:800-804.

86. Han SS, Williams LA, Eggan KC. Constructing and deconstructing stem cell models of neurological disease. Neuron. 2011;70:626-644.

87. Dimos JT, Rodolfa KT, Niakan KK, et al. Induced pluripotent stem cells generated from patients with ALS can be differentiated into motor neurons. Science. 2008;321:1218-1221.
88. Seibler P, Graziotto J, Jeong H, Simunovic F, Klein C, Krainc D Mitochondrial Parkin recruitment is impaired in neurons derived from mutant PINK1 induced pluripotent stem cells. J Neurosci. 2011;31: 5970-5976.

89. Devine MJ, Ryten M, Vodicka P, et al. Parkinson's disease induced pluripotent stem cells with triplication of the $\alpha$-synuclein locus. Nat Commun. 2011;2:440.

90. Nguyen HN, Byers B, Cord B, et al. LRRK2 mutant iPSC-derived DA neurons demonstrate increased susceptibility to oxidative stress. Cell Stem Cell. 2011;8:267-280.

91. Reinhardt P, Schmid B, Burbulla LF, et al. Genetic correction of a LRRK2 mutation in human iPSCs links Parkinsonian neurodegeneration to ERK-dependent changes in gene expression. Cell Stem Cell. 2013;12:354-367.

92. Yue Z, Lachenmayer ML. Genetic LRRK2 models of Parkinson's disease: dissecting the pathogenic pathway and exploring clinical applications. Mov Disord. 2011;26:1386-1397.

93. Schatten G, Mitalipov S. Developmental biology: transgenic primate offspring. Nature. 2009;459:515-516.
Stem Cells and Cloning: Advances and Applications

\section{Publish your work in this journal}

Stem Cells and Cloning: Advances and Applications is an international peer-reviewed, open access journal. Areas of interest in stem cell research include: Embryonic stem cells; Adult stem cells; Blastocysts; Cordblood stem cells; Stem cell transformation and culture; Therapeutic cloning; Umbilical cord blood and bone marrow cells; Laboratory,

\section{Dovepress}

animal and human therapeutic studies; Philosophical and ethical issues related to stem cell research. This journal is indexed on CAS. The manuscript management system is completely online and includes a quick and fair peer-review system. Visit http://www.dovepress.com/ testimonials.php to read real quotes from published authors.

Submit your manuscript here: http://www.dovepress.com/stem-cells-and-cloning-advances-and-applications-journal 